\title{
Categorization of multiple sclerosis relapse subtypes by B cell profiling in the blood
}

\author{
Christopher Hohmann ${ }^{1 \dagger}$, Bianca Milles ${ }^{1 \dagger}$, Michael Schinke ${ }^{1}$, Michael Schroeter ${ }^{2}$, Jochen Ulzheimer ${ }^{3}$, Peter Kraft ${ }^{4,5}$, \\ Christoph Kleinschnitz ${ }^{4}$, Paul V Lehmann ${ }^{6,7}$ and Stefanie Kuerten ${ }^{8^{*}}$
}

\begin{abstract}
Introduction: B cells are attracting increasing attention in the pathogenesis of multiple sclerosis (MS). B cell-targeted therapies with monoclonal antibodies or plasmapheresis have been shown to be successful in a subset of patients. Here, patients with either relapsing-remitting $(n=24)$ or secondary progressive $(n=6)$ MS presenting with an acute clinical relapse were screened for their $B$ cell reactivity to brain antigens and were re-tested three to nine months later. Enzyme-linked immunospot technique (ELISPOT) was used to identify brain-reactive B cells in peripheral blood mononuclear cells (PBMC) directly ex vivo and after $96 \mathrm{~h}$ of polyclonal stimulation. Clinical severity of symptoms was determined using the Expanded Disability Status Scale (EDSS).

Results: Nine patients displayed B cells in the blood producing brain-specific antibodies directly ex vivo. Six patients were classified as B cell positive donors only after polyclonal B cell stimulation. In 15 patients a B cell response to brain antigens was absent. Based on the autoreactive $B$ cell response we categorized MS relapses into three different patterns. Patients who displayed brain-reactive B cell responses both directly ex vivo and after polyclonal stimulation (pattern I) were significantly younger than patients in whom only memory B cell responses were detectable or entirely absent (patterns II and III; $p=0.003$ ). In one patient a conversion to a positive B cell response as measured directly ex vivo and subsequently also after polyclonal stimulation was associated with the development of a clinical relapse. The evaluation of the predictive value of a brain antigen-specific B cell response showed that seven of eight patients (87.5\%) with a pattern I response encountered a clinical relapse during the observation period of 10 months, compared to two of five patients (40\%) with a pattern II and three of 14 patients (21.4\%) with a pattern III response ( $p=0.0005$; hazard ratio 6.08 (95\% confidence interval 1.87-19.77).
\end{abstract}

Conclusions: Our data indicate actively ongoing B cell-mediated immunity against brain antigens in a subset of MS patients that may be causative of clinical relapses and provide new diagnostic and therapeutic options for a subset of patients.

Keywords: B cells, ELISPOT, MS, Predictive value, Relapse

\section{Introduction}

Multiple Sclerosis (MS) is one of the most frequent neurological disorders causing disability in young adults and affects approximately 2.5 million people worldwide $[1,2]$. An interplay between both susceptibility genes and still unknown environmental factors is considered to be causative of the disease. Due to acute inflammatory demyelination and axonal loss with partly structural repair

\footnotetext{
* Correspondence: stefanie.kuerten@uni-wuerzburg.de

${ }^{\dagger}$ Equal contributors

${ }^{8}$ Department of Anatomy and Cell Biology, University of Wuerzburg,

Koellikerstr. 6, 97070 Wuerzburg, Germany

Full list of author information is available at the end of the article
}

and recovery of function, most patients suffer from a relapsing-remitting course.

In order to develop new therapeutic strategies and a better understanding of this autoimmune disorder of the central nervous system (CNS), intensive research efforts dealing with the underlying disease pathomechanisms have been undertaken. For a long time, mainly $\mathrm{T}$ cells were considered as the initiator and perpetuator of the disease. However, during the last two decades, the important role of B cells as antigen presenting cells and producers of autoantibodies in the pathogenesis of MS has increasingly been appreciated [3-5]. In particular, the role of B cells in MS is hardly understood. This is 
surprising because intrathecal antibody synthesis and oligoclonal IgG of yet unknown specificity are a diagnostic hallmark of MS [6]. Clonally expanded B cells persist in the CNS of MS patients [7] and antibody deposition with concomitant complement activation represents the most frequently observed pattern of demyelination in MS brain lesions [8]. Consistently, plasmapheresis can be beneficial in exacerbations in relapsing forms of MS [9]. Although for decades no MS-specific autoantibody has been identified, the discovery of antibodies against the potassium channel KIR4.1 in a substantial proportion of MS patients has revived interest in antibody-mediated autoimmunity in MS [10]. Work performed in MS-like preclinical models suggests a role for B cells in initiating inflammatory responses in the CNS [11] and treatment of relapsing-remitting MS (RRMS) patients with the $\mathrm{B}$ cell depleting monoclonal antibody rituximab rapidly and markedly reduced active CNS inflammation [12]. A similar effectiveness was shown for alemtuzumab [13] and ofatumumab [14]. Nonetheless, today there is still no first-line treatment option in MS that specifically targets B cells and B cell subsets.

The multiple lines of evidence for a contribution of $B$ cells to the disease pathogenesis raise the question whether a sub-typing of patients according to their B cell response in the peripheral blood is not only possible, but may also permit the identification of $\mathrm{B}$ cell-dependent MS, thus paving the way for a target-oriented and individualized therapy.

To this end, we have recently introduced an assay based upon the enzyme-linked immunospot technique (ELISPOT) for the detection of CNS antigen-specific B cells in the blood of patients with MS. These B cells only occurred in MS patients and were absent in healthy donors and in patients with other inflammatory and non-inflammatory neurological diseases as well as other autoimmune disorders [15]. Our previous analyses focused on measurements of the brain antigen-specific B cell response after $96 \mathrm{~h}$ of polyclonal stimulation. Here we extend our findings by introducing a direct ex vivo assay for patients with clinical manifestations of an acute MS relapse. This assay allowed us to visualize acute ongoing B cell immune responses to antigens prominent in the CNS in a subgroup of patients and to correlate this response to clinical relapse parameters.

After binding of a specific antigen to the B cell receptor and its presentation to a corresponding effector $\mathrm{T}$ cell, B cell proliferation and differentiation into plasma cell precursors and memory B cells occur. Whereas antibody producing plasma cells are predominantly located in the bone marrow after emigration from the lymphatic follicles, resting $\mathrm{B}$ lymphocytes recirculate in the body and can be converted into antibody-producing plasma cells with the help of polyclonal stimulation in vitro.
Only in the context of a relapse and at the stage of the emigration from the lymphatic follicles to the bone marrow, plasma cells become detectable in the blood and can be directly analyzed for CNS specificity.

\section{Material and methods \\ Patients}

Thirty patients that were diagnosed with MS according to the 2005 or 2010 McDonald criteria [16], respectively, and undergoing an acute MS relapse were included in the study. Aggravation of persistent disabilities or new clinical symptoms were present for at least $24 \mathrm{~h}$. Exclusion criteria comprised severe accompanying systemic or psychiatric disorders as well as a history of other autoimmune diseases. Subjects who had undergone plasmapheresis or received anti-B cell therapy were also excluded. The cohort of patients analyzed in this study contained both the RRMS $(\mathrm{n}=24)$ and the secondary progressive (SPMS) $(n=6)$ subtype of MS. Details on all patients are provided in Table 1. The research protocol was approved by the institutional ethics committees of the Universities of Cologne and Wuerzburg. For the evaluation of disease severity the Expanded Disability Status Scale (EDSS) was used [17]. Additionally, we employed the tool MS Curves, which is based on the international MSBase Registry and allows the assessment of the individual disease severity [18]. Results are presented as percentiles and evaluated by means of EDSS and time since disease onset in comparison to a large cohort of patients with the same disease duration.

Twenty-two patients had other neurological or other inflammatory neurological diseases (OND/OIND) including one patient with global amnesia, one patient with a psychogenic gait disorder, three patients with headaches, one patient with myopathy, one patient with myasthenia gravis, one patient with epilepsia, three patients with Parkinson's disease, one patient with polyneuropathy, one patient with Guillain-Barré syndrome, one patient with stroke, one patient with subarachnoid hemorrhage, one patient with amyotrophic lateral sclerosis, one patient with neuroborreliosis, one patient with Ménière's disease, one patient with vestibular neuritis, one patient with somatoform pain disorder and two patients with nystagmus.

All patients gave written informed consent and were recruited from a routine clinical care unit at the Departments of Neurology, University Hospitals of Cologne and Wuerzburg and the Caritas-Krankenhaus Bad Mergentheim. Serum samples from healthy donors were obtained from Cellular Technology Limited (Shaker Heights, $\mathrm{OH}$ ). Peripheral blood mononuclear cells (PBMC) from healthy donors were obtained from volunteers at the participating institutions after written informed consent. 
Table 1 Demographic and disease characteristics of the patient cohort

\begin{tabular}{|c|c|c|c|c|c|c|c|c|c|c|}
\hline Pattern & Patient no. & RRMS/SPMS & $\operatorname{Sex}(f / m)$ & $\begin{array}{l}\text { Age at time of } \\
\text { relapse (yrs) }\end{array}$ & $\begin{array}{l}\text { Age at time of } \\
\text { diagnosis (yrs) }\end{array}$ & $\begin{array}{l}\text { Relapse } \\
\text { EDSS }^{*}\end{array}$ & $\begin{array}{l}\text { Treatment } \\
\text { at time of } \\
\text { relapse }\end{array}$ & $\begin{array}{l}\text { Remission } \\
\text { EDSS }^{*}\end{array}$ & $\begin{array}{l}\text { Treatment } \\
\text { at time of } \\
\text { remission }\end{array}$ & $\begin{array}{l}\text { MS severity } \\
\text { (percentile) }^{\ddagger}\end{array}$ \\
\hline I & 1 & RRMS & $f$ & 19 & 17 & 3.0 & GA & 2.0 & $\mathrm{GA}$ & 71 \\
\hline I & 2 & RRMS & $f$ & 30 & 15 & 4.0 & IFN & 3.0 & IFN & 51 \\
\hline I & 3 & RRMS & f & 18 & 17 & 4.0 & None & 4.0 & None & 91 \\
\hline I & 4 & RRMS & $f$ & 42 & 27 & 6.0 & GA & 4.0 & GA & 66 \\
\hline I & 5 & RRMS & $f$ & 32 & 32 & 3.0 & None & 2.5 & None & 81 \\
\hline I & 6 & RRMS & f & 29 & 29 & 4.5 & IFN & 4.0 & IFN & 91 \\
\hline I & 7 & RRMS & f & 24 & 24 & 2.0 & None & 1.5 & None & 51 \\
\hline I & 8 & RRMS & $f$ & 32 & 32 & 4.0 & None & 2.0 & None & 72 \\
\hline I & 9 & SPMS & $f$ & 25 & 20 & 4.0 & FM & 4.5 & None & 91 \\
\hline II & 10 & RRMS & f & 22 & 21 & 2.0 & IFN & 2.0 & NA & 73 \\
\hline II & 11 & RRMS & $f$ & 47 & 47 & 3.5 & None & 2.0 & IFN & 72 \\
\hline II & 12 & RRMS & $f$ & 34 & 31 & 4.0 & None & 3.0 & IFN & 79 \\
\hline II & $13^{\S}$ & RRMS & $f$ & 59 & 40 & 6.0 & None & I & I & I \\
\hline II & 14 & SPMS & $\mathrm{m}$ & 36 & 32 & 6.0 & Mitox & 5.0 & Mitox & 92 \\
\hline II & 15 & SPMS & $f$ & 53 & 50 & 5.5 & None & 5.5 & None & 93 \\
\hline III & 16 & RRMS & $f$ & 32 & 32 & 2.0 & None & 2.0 & IFN & 73 \\
\hline III & 17 & RRMS & $f$ & 49 & 38 & 6.0 & None & 6.0 & FM & 91 \\
\hline III & 18 & SPMS & $\mathrm{m}$ & 52 & 37 & 5.5 & None & 5.5 & None & 80 \\
\hline III & $19^{\S}$ & RRMS & $f$ & 38 & 23 & 6.5 & None & / & I & / \\
\hline III & 20 & RRMS & f & 48 & 47 & 4.0 & IFN & 3.5 & IFN & 91 \\
\hline III & 21 & SPMS & $\mathrm{m}$ & 52 & 41 & 2.5 & GA & 2.5 & FM & 51 \\
\hline III & 22 & SPMS & $f$ & 54 & 35 & 7.5 & None & 7.0 & None & 92 \\
\hline III & 23 & RRMS & $\mathrm{m}$ & 40 & 40 & 2.0 & None & 2.0 & IFN & 72 \\
\hline III & 24 & RRMS & $\mathrm{m}$ & 61 & 61 & 2.0 & None & 4.0 & IFN & 91 \\
\hline III & 25 & RRMS & $f$ & 31 & 30 & 2.0 & IFN & 1.0 & IFN & 38 \\
\hline III & 26 & RRMS & $f$ & 21 & 21 & 3.5 & None & 1.0 & IFN & 37 \\
\hline III & 27 & RRMS & f & 18 & 18 & 6.0 & None & 1.5 & None & 51 \\
\hline III & 28 & RRMS & f & 45 & 45 & 2.0 & None & 2.0 & None & 72 \\
\hline III & 29 & RRMS & $\mathrm{m}$ & 52 & 27 & 4.5 & None & 4.5 & None & 66 \\
\hline III & 30 & RRMS & $f$ & 43 & 43 & 6.0 & FA & 6.0 & FA & 94 \\
\hline
\end{tabular}

EDSS = Expanded Disability Status Scale; FA = fumaric acid; FM = fingolimod; GA = glatiramer acetate; IFN = interferon- $\beta ;$ Mitox = mitoxantrone; NA = natalizumab; RRMS = relapsing-remitting MS; SPMS = secondary progressive MS.

"Scores on the EDSS range from 0 to 10 , with higher scores indicating a greater degree of disability.

${ }^{\ddagger} \mathrm{MS}$ severity refers to the percentile rank of each individual study patient compared to a matched MS cohort of the MSBase Registry. Values were determined using MS Curves [18].

§These patients were lost to follow-up.

\section{Enzyme-linked immunospot technique (ELISPOT)}

PVDF membrane 96-well ELISPOT plates (Merck Millipore, Darmstadt, Germany) were coated overnight with fresh frozen whole normal human brain lysate (30 $\mu \mathrm{g} / \mathrm{ml}$; Novus Biologicals, Littleton, CO), dissolved in sterile phosphate-buffered saline (PBS). We deliberately chose whole brain lysate as antigenic target taking into account that each individual patient recognizes a multitude of different tissue antigens. We suggest that the use of single antigens would have been counterintuitive also following the epitope spreading hypothesis of MS. Therefore, and particularly from a clinical point of view, the approach presented here should be the most feasible. Coating with $10 \%$ fetal bovine serum (FBS; Biochrom, Berlin, Germany) in sterile PBS served as negative control, respectively. The ELISPOT findings were controlled for the quantitative frequency of B cells in each sample by including measurements for total IgG in each donor. To this end, plates were coated with anti-human Igk (SouthernBiotech, Birmingham, AL) at $10 \mu \mathrm{g} / \mathrm{ml}$. Both 
whole normal human brain lysate and anti-human Igk were titrated to their optimal concentration for use in B cell ELISPOT assays. After PBMC isolation from the blood by Ficoll-Paque (GE Healthcare Europe GmbH, Freiburg, Germany) density gradient centrifugation, PBMC were diluted in complete RPMI medium consisting of RPMI1640 (Lonza, Cologne, Germany) and 10\% FBS, 1\% L-glutamine (Sigma, Schnelldorf, Germany) and 1\% penicillin/streptomycin (Sigma) to a concentration of $3 \times 10^{6}$ cells $/ \mathrm{ml}$. Plates were blocked with $10 \%$ FBS in sterile PBS for $2 \mathrm{~h}$ at room temperature. For direct ex vivo testing $3 \times$ $10^{5}$ PBMC were plated per well and afterwards incubated for $24 \mathrm{~h}$ at $37^{\circ} \mathrm{C}$ and $7 \% \mathrm{CO}_{2}$. In order to stimulate $\mathrm{B}$ cells polyclonally, PBMC were cultured at a concentration of $3 \times 10^{6}$ cells $/ \mathrm{ml}$ for $96 \mathrm{~h}$ in complete RPMI-1640 medium that contained $\beta$-mercaptoethanol (Sigma), the toll-like receptor 7/8 agonist R-848 (Enzo Life Sciences, Inc., Farmingdale, NY) and IL-2 (Peprotech, Hamburg, Germany). For testing of polyclonally stimulated B cells one million cells were plated per well and incubated for $26 \mathrm{~h}$ at $37^{\circ} \mathrm{C}$ and $7 \% \mathrm{CO}_{2}$. Biotinylated anti-human IgG (Hybridoma Reagent Laboratory, Baltimore, MD) diluted in $1 \%$ bovine serum albumin (BSA) solution was used as a detection antibody at $0.2 \mu \mathrm{g} / \mathrm{ml}$. For the direct ex vivo testing biotinylated anti-human IgM (Hybridoma Reagent Laboratory) at a concentration of $0.05 \mu \mathrm{g} /$ $\mathrm{ml}$ was additionally used. All plates were developed with Vector Blue substrate (Vector Laboratories, Burlingame, CA) after incubation with streptavidin-alkaline phosphatase (AP) (Dako, Glostrup, Denmark) at 1:1000 dilution. Spots were analyzed on an ImmunoSpot ${ }^{\circ}$ Series 6 Analyzer (Cellular Technology Limited).

\section{Enzyme-linked immunosorbent assays (ELISA)}

ELISA plates (Thermo Scientific, Schwerte, Germany) were coated overnight with whole normal human brain lysate (Novus Biologicals; $10 \mu \mathrm{g} / \mathrm{ml}$ ) or anti-human Igk (SouthernBiotech; $2.5 \mu \mathrm{g} / \mathrm{ml}$ ), respectively, both diluted in PBS or with PBS alone. As for the ELISPOT assay, whole normal human brain lysate and anti-human Igk were titrated to their optimal concentration for use in the antibody ELISA. Plates were blocked with 10\% FBS in PBS containing $0.05 \%$ Tween 20 for $2 \mathrm{~h}$ at room temperature. The plates were incubated overnight with serum at $4^{\circ} \mathrm{C}$. All serum samples were diluted 1:400 in 10\% FBS solution containing $0.05 \%$ Tween 20 detergent. Biotinylated anti-human IgG (Hybridoma Reagent Laboratory) diluted in $0.5 \% \mathrm{FBS} / 0.05 \%$ Tween 20 solution was used as a detection antibody at $0.05 \mu \mathrm{g} / \mathrm{ml}$. All plates were developed with tetramethylbenzidine substrate (eBioscience, Frankurt, Germany) after incubation with streptavidin-horseradish peroxidase (eBioscience) at 1:1000 dilution. The reaction was stopped with $0.16 \mathrm{M}$ sulphuric acid and the optical density (OD) in the wells was read at $450 \mathrm{~nm}$ using a Perkin Elmer Victor 31420 Multilabel Counter and Wallac 1420 software version 3.00 revision 5 .

\section{Statistical analysis}

The cut-off value for a positive $B$ cell response measured directly ex vivo was determined in a cohort of $\mathrm{n}=17$ healthy donors and was set to $>1.6$ spots (mean value + 3 standard deviations). Twelve of the healthy donors were retested on the consecutive day with similar results to account for day-to-day variation. The cut-off value for a brain antigen-specific B cell response after polyclonal stimulation was set to $>4.5$ spots as previously established [15]. Serum samples were considered positive when the OD was at least five standard deviations above the mean value of a cohort of 69 healthy control donors. The characteristics of the patients and their disease were compared among the groups according to the B cell response status with the use of the Wilcoxon rank-sum test, which was also used to determine differences in spot size morphology. The cumulative risk of the development of a MS relapse was calculated for each group according to the Kaplan-Meier method, and differences between the groups were evaluated in a univariate analysis with the log-rank test. The Cox proportional-hazards model was used to assess the predictive value of a positive brain-specific B cell response. The relative risk of the development of a MS relapse is expressed as a hazard ratio and $95 \%$ confidence interval. P-values of less than 0.05 were considered to indicate statistical significance.

\section{Results}

PBMC from 30 patients with MS experiencing an acute relapse were analyzed for their response to brain antigen using the ELISPOT technique. In order to differentiate between an acute and a memory B cell response, we introduced two different assay types. In a direct ex vivo approach PBMC were incubated on the plates for $24 \mathrm{~h}$ immediately after separation from the blood sample without any prestimulation. Alternatively, PBMC were tested after $96 \mathrm{~h}$ of polyclonal stimulation with R-848, IL-2 and $\beta$-mercaptoethanol, which is an established method for the activation of resting memory B cells [19]. Secreted antibodies were captured on the ELISPOT plates and visualized as spots that corresponded to the numbers of brain antigen-specific B cells.

Distinct size morphology of B cell spots produced directly ex vivo and after polyclonal stimulation in ELISPOT assays In a total of nine patients brain antigen-specific B cells could be detected in the blood directly ex vivo and after polyclonal stimulation (Table 2). We compared the morphology of spots produced directly ex vivo and after polyclonal stimulation using a specialized ImmunoSpot $^{\circ}$ image 
Table 2 Distribution of $B$ cell response patterns in patients experiencing an acute MS relapse ${ }^{*}$

\begin{tabular}{llll}
\hline Variable & Pattern I & Pattern II & Pattern III \\
\hline $\begin{array}{l}\text { No. of patients } \\
\text { Age - yrs }\end{array}$ & 9 & 6 & 15 \\
$\quad$ Mean & $27.9 \pm 7.4$ & $41.8 \pm 13.7$ & $42.4 \pm 12.4$ \\
$\quad$ Range & $18-42$ & $22-59$ & $18-61$ \\
Female sex - no. (\%) & $9(100)$ & $5(83.3)$ & $10(66.7)$ \\
EDSS in remission ${ }^{\dagger}$ & & & \\
$\quad$ Mean & $3.1 \pm 1.1$ & $3.5 \pm 1.7^{\ddagger}$ & $3.5 \pm 2.0^{\ddagger}$ \\
$\quad$ Range & $1.5-5.0$ & $2.0-5.5$ & $1.0-7.0$ \\
MS severity & & & \\
$\quad$ Mean & $73.9 \pm 16.0$ & $81.8 \pm 10.1^{\ddagger}$ & $71.4 \pm 20.2^{\ddagger}$ \\
$\quad$ Range & $51-91$ & $72-93$ & $37-94$ \\
RRMS/SPMS & $8 / 1$ & $4 / 2$ & $12 / 3$ \\
\hline
\end{tabular}

EDSS = Expanded Disability Status Scale; RRMS = relapsing-remitting MS; SPMS = secondary progressive MS; SD = standard deviation.

"Plus-minus values are means $\pm S D$.

${ }^{\dagger}$ Scores on the EDSS range from 0 to 10 , with higher scores indicating a greater degree of disability.

${ }^{\ddagger}$ One patient was lost to follow-up.

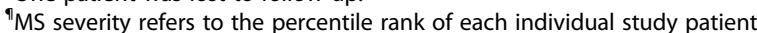
compared to a matched MS cohort of the MSBase Registry. Values were determined using MS Curves [18].

analysis software. Spots that were produced directly ex vivo were much more distinct and significantly smaller than spots produced after $96 \mathrm{~h}$ of polyclonal stimulation (compare a mean spot size of $0.008282 \mathrm{~mm}^{2} \pm 0.00852 \mathrm{~mm}^{2}$ to $0.033343 \mathrm{~mm}^{2} \pm 0.052619 \mathrm{~mm}^{2} ; \mathrm{p}<0.001$ ) (Figure 1). These results underline the notion that spots detected directly ex vivo correspond to antibodies produced by recently activated and still recirculating plasma cells, while spots produced after polyclonal stimulation are derived from resting memory B cells that produce significantly larger spots following in vitro reactivation.

Brain-reactive antibodies are detectable in the serum of patients experiencing an acute clinical relapse of MS and displaying a positive $\mathrm{B}$ cell ELISPOT response directly ex vivo A positive response in directly ex vivo performed $\mathrm{B}$ cell ELISPOT assays should correspond to in vivo ongoing B cell (re)activation characterized by the secretion of antibodies by plasma cells. To confirm this assumption, we additionally obtained serum samples from $n=12$ patients of our cohort during relapse and performed ELISA analysis for the detection of brain-reactive antibodies. Results are shown in Table 3. Of the 12 patients, four were characterized by a positive response in directly ex vivo performed $\mathrm{B}$ cell ELISPOT assays. These patients also displayed CNS antigen-specific antibodies in the serum as measured by ELISA. All of the eight patients that were tested negative in the directly ex vivo performed ELISPOT were also tested negative in the ELISA.
Ongoing brain-specific B cell activity is detectable in the blood in a subset of patients with an acute disease relapse In addition to the nine patients that showed a positive $B$ cell response both directly ex vivo and after polyclonal stimulation, we identified six of 30 patients that did not show any $B$ cell activity associated with the relapse, but were classified as B cell positive donors only after polyclonal stimulation. The remaining 15 of 30 patients displayed brain antigen-specific B cells neither in direct ex vivo assays nor after $96 \mathrm{~h}$ of stimulation. These data suggest that the MS patients tested in our study fall into three different categories, depending on the presence of an actively ongoing and/or CNS antigen-specific memory $\mathrm{B}$ cell response in the blood. These categories are summarized as "patterns" in Tables 1 and 2 and Figure 2. No significant differences were found between the patterns in relation to relapse or disease severity (Table 2). However, patients who were classified as "pattern I" with a positive B cell response both directly ex vivo and after polyclonal stimulation were significantly younger than the cohort of patients represented by both pattern II and III ( $p=0.003)$. In order to delineate that the CNS antigenspecific B cell response was not a transient phenomenon, but a characteristic feature of a disease subtype, we retested 21 MS patients in clinical remission three to nine months after relapse. In 17 of 21 patients the CNS antigen-specific $\mathrm{B}$ cell response detected after polyclonal stimulation was comparable to the results obtained during relapse. Four patients who had been tested negative initially, now showed a positive response. Loss of a brain antigen-specific B cell response in previously positive patients was not observed. Importantly, the formerly evident B cell activity in nine of 30 patients as measured directly ex vivo was absent in remission. Brain antigen-specific $B$ cells were also absent directly ex vivo in healthy donors $(\mathrm{n}=17)$ and patients with other neurological or other inflammatory neurological diseases $(n=22)$.

Association between the development of brain-specific B cell responses in the blood and acute disease reactivation One interesting finding pertained to a patient who originally did not display any CNS antigen-specific B cell responses directly ex vivo and after polyclonal stimulation. In this patient clinical examination three months after relapse revealed a recovery of function and no signs for a renewed clinical disease exacerbation despite the persistence of paresthesia. However, a positive brain antigenspecific B cell response was evident in direct ex vivo ELISPOT testing indicating recent immune reactivation. Ten days later the patient was admitted to the hospital with symptoms of a clinical relapse including deficits in visual, cerebellar, sensory as well as motor functions. ELISPOT analysis confirmed the presence of plasma cells actively secreting brain antigen-reactive antibodies. The 

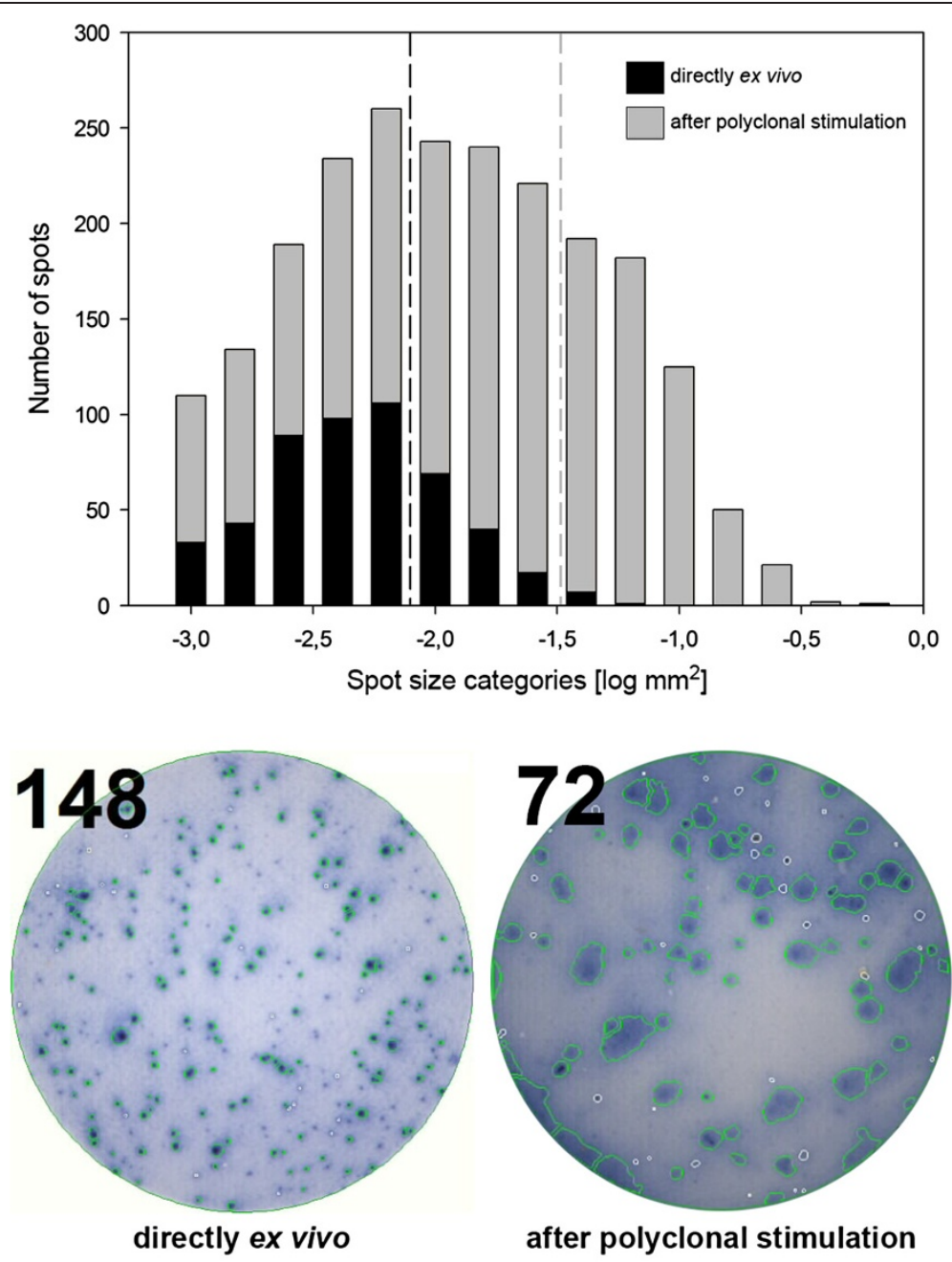

$$
\bar{x}=0.008 \mathrm{~mm}^{2}
$$
$\min 0.000379 \mathrm{~mm}^{2}$ $\max 0.070483 \mathrm{~mm}^{2}$

$$
\begin{gathered}
\bar{x}=0.033 \mathrm{~mm}^{2} \\
\min 0.000319 \mathrm{~mm}^{2} \\
\max 0.442321 \mathrm{~mm}^{2}
\end{gathered}
$$

Figure 1 Morphology of B cell spots measured directly ex vivo and after polyclonal stimulation. The histogram shows the differences in the distribution of B cell spots measured directly ex vivo (black bars) or after $96 \mathrm{~h}$ of polyclonal stimulation (colored bars) in ELISPOT assays. The dashed lines indicate the spot size means in the two groups. A total of 524 spots were analyzed directly ex vivo compared to 2307 spots after polyclonal stimulation using the ImmunoSpot ${ }^{\circledR}$ software version 5.1.36 Professional DC. The images show representative wells for assays performed directly ex vivo or after polyclonal stimulation. The numbers in the left upper corner indicate the spot counts for the two individual wells. The mean spot size measured directly ex vivo was $0.008 \mathrm{~mm}^{2}$ compared to $0.033 \mathrm{~mm}^{2}$ after polyclonal stimulation. Minimum spot sizes were comparable. The maximum spot size was $0.070483 \mathrm{~mm}^{2}$ in direct ex vivo assays compared to a size of $0.442321 \mathrm{~mm}^{2}$ measured after polyclonal stimulation.

patient was examined at three subsequent time points during which we were able to demonstrate the disappearance of brain antigen-specific plasma cells from the blood. At the same time, a brain antigen-specific memory B cell response became detectable (Figure 3). The dramatic drop in the number of $\mathrm{B}$ cell spots measured directly ex vivo and after polyclonal stimulation within four days between the third and fourth measurement may be explained either by the high dose intravenous glucocorticoid therapy that was administered at the time point of relapse for three consecutive days [20] and/or by the migration of the autoreactive $B$ cells into the target tissue, that is the CNS.

\section{A positive brain-specific $B$ cell response in the blood is predictive of a subsequent relapse}

The association between a positive brain-reactive B cell response in the blood in direct ex vivo assays and the development of a consecutive relapse as shown for one case in Figure 3 suggests that the presence of brain-reactive B cells in the blood could be linked to a higher relapse rate. 
Table 3 Measurements of brain-specific serum antibodies by ELISA

\begin{tabular}{ccccccc}
\hline $\begin{array}{l}\text { Patient } \\
\text { no. }\end{array}$ & $\begin{array}{l}\text { Direct } \\
\text { ex vivo } \\
\text { ELISPOT } \\
\text { response } \\
\text { [spot number] }\end{array}$ & $\begin{array}{l}\text { OD } \\
\text { Brain } \\
\text { antigen* }\end{array}$ & $\begin{array}{l}\text { SD } \\
\text { Brain } \\
\text { antigen }\end{array}$ & $\begin{array}{l}\text { OD } \\
\text { Total } \\
\text { IgG }\end{array}$ & $\begin{array}{l}\text { SD } \\
\text { Total } \\
\text { lgG }\end{array}$ & $\begin{array}{l}\text { OD } \\
\text { brain } \\
\text { antigen/ } \\
\text { OD total } \\
\text { IgG }\end{array}$ \\
\hline $\mathbf{1}$ & $26.0 \pm 4.2$ & 1.593 & 0.136 & 2.748 & 0.04 & 0.58 \\
$\mathbf{2}$ & $9.0 \pm 6.4$ & 0.974 & 0.094 & 2.609 & 0.084 & 0.373 \\
$\mathbf{3}$ & $86.5 \pm 41.7$ & 0.852 & 0.107 & 2.693 & 0.049 & 0.316 \\
$\mathbf{4}$ & $13.0 \pm 2.8$ & 1.231 & 0.084 & 2.558 & 0.132 & 0.48 \\
$\mathbf{1 0}$ & $0.0 \pm 0.0$ & 0.468 & 0.014 & 2.92 & 0.086 & 0.16 \\
$\mathbf{1 1}$ & $0.0 \pm 0.0$ & 0.437 & 0.034 & 2.636 & 0.024 & 0.166 \\
$\mathbf{1 2}$ & $0.0 \pm 0.0$ & 0.108 & 0.000 & 2.673 & 0.024 & 0.04 \\
$\mathbf{1 6}$ & $0.0 \pm 0.0$ & 0.235 & 0.057 & 2.608 & 0.042 & 0.09 \\
$\mathbf{1 7}$ & $0.0 \pm 0.0$ & 0.576 & 0.013 & 2.724 & 0.032 & 0.211 \\
$\mathbf{1 8}$ & $0.0 \pm 0.0$ & 0.147 & 0.034 & 2.837 & 0.112 & 0.052 \\
$\mathbf{2 0}$ & $0.0 \pm 0.0$ & 0.369 & 0.047 & 2.729 & 0.12 & 0.135 \\
$\mathbf{2 2}$ & $0.0 \pm 0.0$ & 0.658 & 0.060 & 2.783 & 0.033 & 0.236 \\
\hline
\end{tabular}

ELISA = enzyme-linked immunosorbent assay; ELISPOT = enzyme-linked immunospot technique; $\mathrm{OD}=$ optical density; $\mathrm{SD}=$ standard deviation.

*All samples were tested in duplicate wells and are represented as mean medium-subtracted values. The cut-off value for a positive response was calculated from the means of a group of 69 healthy control donors + 5 SD (OD brain antigen/OD total $\lg \mathrm{G}>0.307$ ).
To test this hypothesis, we followed $n=8$ patients that displayed a brain-reactive $B$ cell response in the blood directly ex vivo and after polyclonal stimulation (pattern I), $\mathrm{n}=5$ patients that displayed brain-reactive $\mathrm{B}$ cells only after polyclonal stimulation (pattern II) and $n=14$ patients with a negative B cell response in both assays (pattern III). The patients were followed for a period of ten months and the time to the next relapse after initial testing was recorded. Data are summarized in Table 4. The Kaplan-Meier plot shows that the relapse-free interval in patients that were tested positive in direct ex vivo ELISPOT assays was significantly shorter than in patients that were classified as pattern II or III $(\mathrm{p}=0.0005)$ (Figure 4). There was no significant difference between patients with pattern II versus pattern III $(\mathrm{p}=0.348)$. The hazard ratio for the development of a consecutive relapse in the setting of a positive direct ex vivo brain-reactive B cell response in the blood (pattern I) compared to patients with pattern II or III was 6.08 (95\% confidence interval 1.87-19.77).

\section{Discussion}

In the pathogenesis of MS, multiple lines of evidence indicate an important role of $\mathrm{B}$ cells and autoantibodies [21-24]. For decades, intensive research efforts were made to identify the target antigen in MS, but antibodies against myelin components or other structures prominent in the

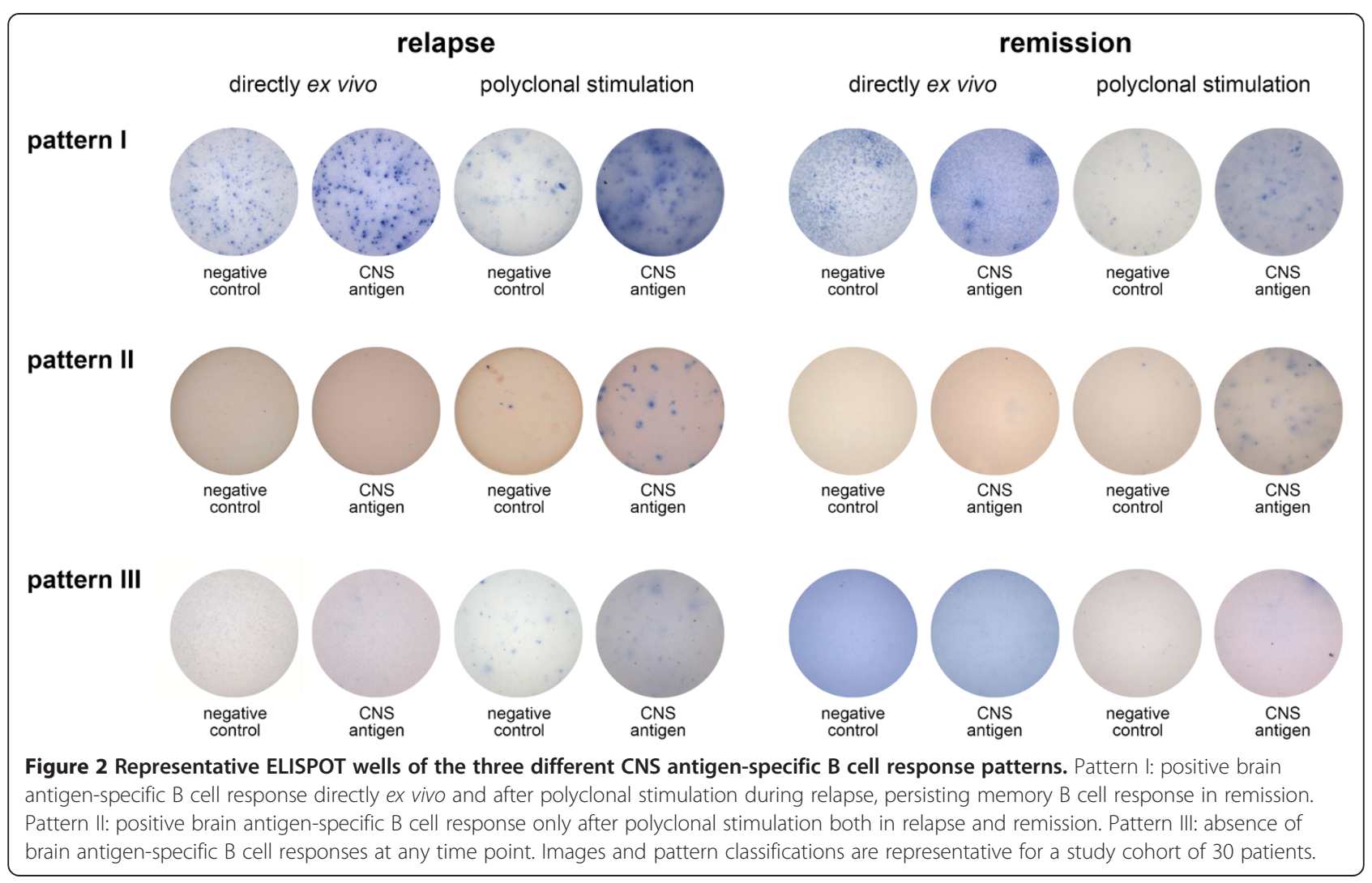




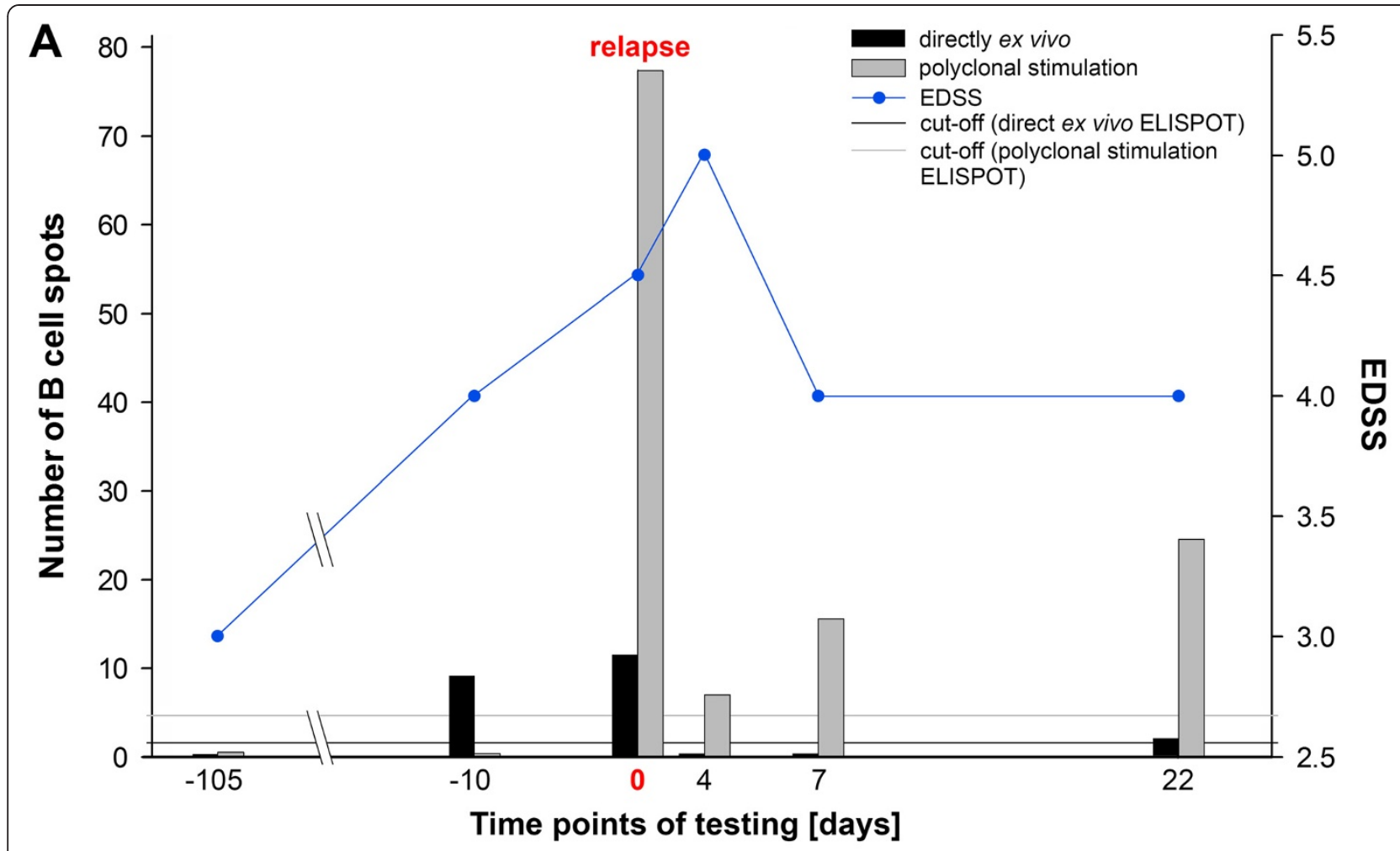

B

105 days before relapse

10 days before relapse
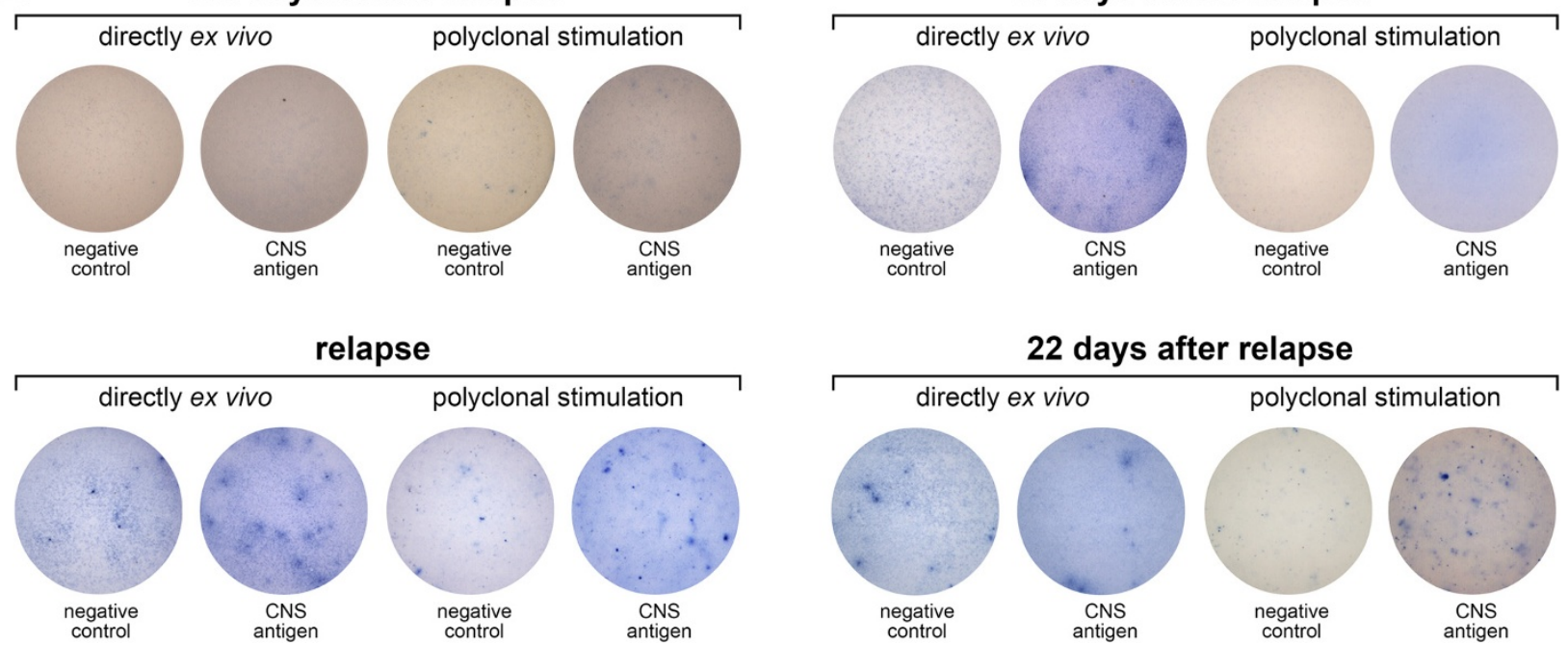

22 days after relapse

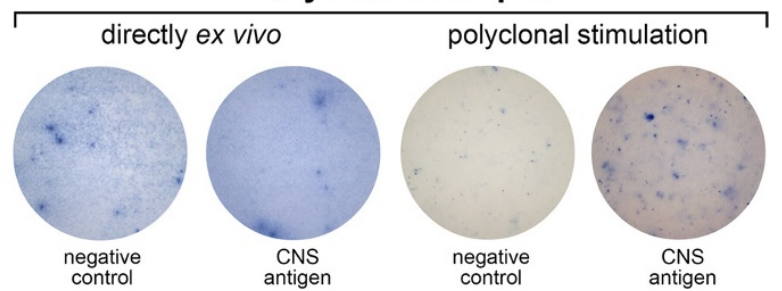

Figure 3 ELISPOT results of a patient showing a conversion from pattern III to pattern I. Panel $\mathbf{A}$ shows the number of B cell spots measured in ELISPOT assays directly ex vivo and after $96 \mathrm{~h}$ of polyclonal stimulation in an individual patient on six consecutive time points. The severity of clinical disease is represented by the EDSS score that is referred to by the line graph. Representative well images of four different time points are shown in Panel $\mathbf{B}$ depicting the development of a brain antigen-specific B cell response in the course of the disease.

CNS were also frequently found in other neurological diseases and/or healthy individuals [4,25]. The assumption that antibodies are pathogenic in the development of MS is mainly supported by histopathological findings that provided evidence for the frequent deposition of immunoglobulins and complement factors in MS brain lesions [8]. In the past an association between the neuropathological pattern II defined by Lucchinetti et al. and a benefit from plasma exchange was suggested [26] and treatment with the B cell-specific monoclonal antibodies 


\begin{tabular}{|c|c|c|c|}
\hline Time [months] & Pattern I & Pattern II & Pattern III \\
\hline 0 & 8 & 5 & 14 \\
\hline 1 & 7 & 5 & 14 \\
\hline 2 & 7 & 5 & 14 \\
\hline 3 & 5 & 5 & 14 \\
\hline 4 & 4 & 3 & 14 \\
\hline 5 & 3 & 3 & 12 \\
\hline 6 & 2 & 3 & 12 \\
\hline 7 & 2 & 3 & 12 \\
\hline 8 & 1 & 3 & 12 \\
\hline 9 & 1 & 3 & 11 \\
\hline 10 & 1 & 3 & 11 \\
\hline
\end{tabular}

rituximab, alemtuzumab or ofatumumab were effective in ameliorating disease severity by means of reduction in the number of total gadolinium-enhancing magnetic resonance imaging (MRI) lesions as well as lower annualized relapse rates [12-14]. It has initially been suggested that in particular antibodies against myelin oligodendrocyte glycoprotein (MOG) and myelin basic protein (MBP) were predictive of a conversion from a clinically-isolated syndrome (CIS) to clinically definite MS [27]. However, a subsequent corroboration of these results failed [28]. Here we show that the presence of a brain-specific memory B cell response in the blood as measured by ELISPOT was

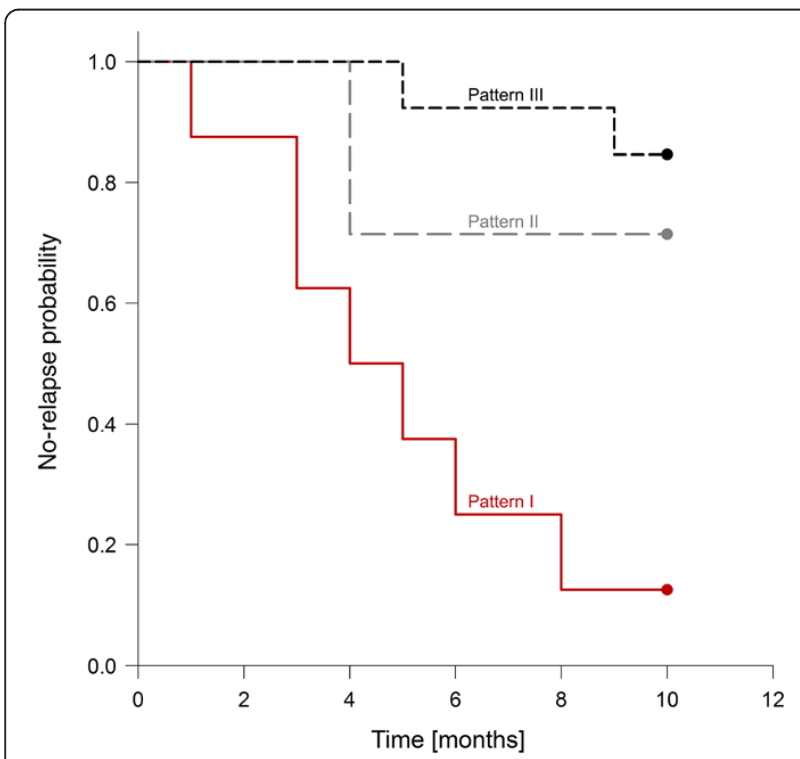

Figure 4 Kaplan-Meier estimates of the risk of a MS relapse according to the presence of brain-specific $B$ cells in the blood. $P=0.0005$ for the comparison between patients who were tested positive for direct ex vivo brain-specific B cells (pattern I) and patients who were tested negative (patterns II and III). associated with an increased risk of the development of a MS relapse.

In our previous work we have demonstrated that the detection of brain antigen-specific B cells in the PBMC population permitted the identification of a B cell-dependent subtype of MS [15]. These data were in line with earlier reports that showed the presence of proteolipid protein (PLP)- and MOG-specific B cells in the blood and cerebrospinal fluid (CSF) of patient with MS using the ELISPOT approach $[29,30]$. The data presented here extend these findings not only by presenting the predictive value of this test, but also by the introduction of a direct ex vivo assay that indicated actively ongoing disease and was associated with clinical disease reactivation in a fraction of patients. It is tempting to speculate that the presence of brain-reactive $B$ cell responses in the blood can be used to subdivide MS patients into different categories as suggested in the current study. A categorization of patients has already been done following different patterns of demyelination in brain lesions and the most frequently observed pattern was characterized by the deposition of antibodies. Interindividual heterogeneity in the patterns of demyelinative pathology has been suggested [8]. Our data support this concept, but imply that there might also be intraindividual heterogeneity in regard to the brain-specific $B$ cell response over the course of the disease.

Acute clinical relapses of MS often lead to the deterioration of clinical symptoms and the failure of functional CNS systems. As yet, the evidence-based standard treatment for MS relapses is a high-dose intravenous glucocorticosteroid pulse therapy. Since relapse treatment can only be initiated when new clinical symptoms of MS are evident and persist, there is always a risk of the development of irreversible deficits. The ability to detect relapses before they become clinically evident and their consecutive early treatment would provide an option to prevent the accumulation of CNS damage. A subtyping of blood immune responses as suggested here might be one possible option along these lines. Even if the CSF is also relatively easy to access and it might be argued that immune responses in the CSF reflect the pathogenic processes in the CNS more closely, the risks of side effects and the ethical problems with exposing patients to repeated spinal taps emphasize the clinical and practical advantage of a test that can be performed on peripheral blood.

\section{Conclusion}

The data presented here strengthen the central role of $\mathrm{B}$ cells in the immune pathogenesis of MS. It is conceivable that our results will help to identify patients with B cell-/antibody-dependent MS and relapses, thereby guiding the development and use of B cell-directed therapeutic strategies. It remains to be elucidated if the detection of recirculating $\mathrm{B}$ cells that produce $\mathrm{CNS}$-specific 
antibodies ex vivo will allow the diagnosis of MS reactivation even before the occurrence of clinically evident symptoms, which would help to facilitate the initiation of early treatment that could potentially include plasmapheresis [26]. Finally, the detection of antibody-producing B cells in MS patients corroborates the autoimmune hypothesis of the disease and its association with clinical disease parameters.

\section{Abbreviations}

AP: Alkaline phosphatase; BSA: Bovine serum albumin; CIS: Clinically-isolated syndrome; CNS: Central nervous system; CSF: Cerebrospinal fluid;

EDSS: Expanded disability status scale; ELISA: Enzyme-linked immunosorbent assay; ELISPOT: Enzyme-linked immunospot technique; FBS: Fetal bovine serum; MBP: Myelin basic protein; MOG: Myelin oligodendrocyte glycoprotein; MRI: Magnetic resonance imaging; MS: Multiple sclerosis; OD: Optical density; OND: Other neurological diseases; OIND: Other inflammatory neurological diseases; PBMC: Peripheral blood mononuclear cells; PBS: Phosphate-buffered saline; PLP: Proteolipid protein; RRMS: Relapsing-remitting multiple sclerosis; SD: Standard deviation; SPMS: Secondary progressive multiple sclerosis.

\section{Competing interests}

Dr. Kuerten served as paid speaker for Bayer HealthCare and received grant support from Bayer HealthCare, Teva and Novartis. Dr. Kuerten and Dr. Lehmann have filed a patent (U.S. 14/113,740). Dr. Schroeter has got personal and institutional compensations from Astellas Pharma, Bayer HealthCare, Baxter, Biogen Idec, GlaxoSmithKline, Grifols, Janssen-Cilag, Merck, Novartis, Pfizer, Roche, Sanofi and Teva. Dr. Lehmann is the CEO of Cellular Technology Limited, Shaker Heights, OH, USA. Dr. Kleinschnitz received personal and/or institutional compensations from Bayer Healthcare, Biogen Idec, Biotronik, Boehringer Ingelheim, Bristol Myers Squibb, Eisai, Genzyme, Merck Serono, Novartis, Pfizer, Sanofi, Siemens and Teva.

\section{Authors' contributions}

$\mathrm{CH}$ recruited the patients, performed the experiments, analyzed and interpreted the data and drafted the manuscript. BM recruited the patients, performed the experiments, analyzed and interpreted the data and drafted the manuscript. MS, MS, JU, PK and CK analyzed and interpreted the data. PVL analyzed and interpreted the data, participated in administrative, technical, or material support and supervised the study. SK conceived of the study concept and design, analyzed and interpreted the data, performed the experiments, drafted the manuscript, performed statistical analysis, participated in administrative, technical, or material support, supervised the study and obtained the funding. All authors read and approved the final manuscript. $\mathrm{CH}$ and $\mathrm{BM}$ contributed equally to this work.

\section{Acknowledgements}

We wish to thank all our patients for participating in this study. We are grateful to Michael Christof for help with the figure design. This work was funded by grants from Bayer HealthCare and Novartis [grants to S.K.]. This publication was funded by the German Research Foundation (DFG) and the University of Wuerzburg in the funding programme Open Access Publishing.

\footnotetext{
Author details

'Department of Anatomy I, University of Cologne, Joseph-Stelzmann-Str. 9, 50931 Cologne, Germany. ${ }^{2}$ Department of Neurology, University Hospitals of Cologne, Kerpener Str. 62, 50937 Cologne, Germany. ${ }^{3}$ Department of Neurology, Caritas-Krankenhaus Bad Mergentheim, Uhlandstr. 7, 97980 Bad Mergentheim, Germany. ${ }^{4}$ Department of Neurology, University Hospitals of Wuerzburg, Josef-Schneider-Str. 11, 97080 Wuerzburg, Germany. ${ }^{5}$ Institute of Clinical Epidemiology and Biometry, Comprehensive Heart Failure Center, University of Wuerzburg, Josef-Schneider-Str. 2, 97080 Wuerzburg, Germany. ${ }^{6}$ Department of Pathology, Case Western Reserve University, 2103 Cornell Rd., Cleveland, OH 44106, USA. ${ }^{7}$ Cellular Technology Limited, 20521 Chagrin Blvd, Shaker Heights, OH 44122, USA. ${ }^{8}$ Department of Anatomy and Cell Biology, University of Wuerzburg, Koellikerstr. 6, 97070 Wuerzburg, Germany.
}

Received: 17 July 2014 Accepted: 5 September 2014

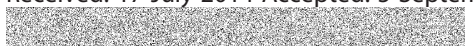

\section{References}

1. Noseworthy JH, Lucchinetti C, Rodriguez M, Weinshenker BG (2000) Multiple sclerosis. N Engl J Med 343:938-952

2. Compston A, Coles A (2008) Multiple sclerosis. Lancet 372:1502-1517

3. Weber MS, Hemmer B, Cepok S (2011) The role of antibodies in multiple sclerosis. Biochim Biophys Acta 1812:239-245

4. Reindl M, Linington C, Brehm U, Egg R, Dilitz E, Deisenhammer F, Poewe W, Berger T (1999) Antibodies against the myelin oligodendrocyte glycoprotein and the myelin basic protein in multiple sclerosis and other neurological diseases: a comparative study. Brain 122:2047-2056

5. Storch MK, Piddlesden S, Haltia M, livanainen M, Morgan $P$, Lassmann $H$ (1998) Multiple sclerosis: in situ evidence for antibody- and complement-mediated demyelination. Ann Neurol 43:465-471

6. Stangel M, Fredrikson S, Meinl E, Petzold A, Stüve O, Tumani H (2013) The utility of cerebrospinal fluid analysis in patients with multiple sclerosis. Nat Rev Neurol 9:267-276

7. Krumbholz M, Derfuss T, Hohlfeld R, Meinl E (2012) B cells and antibodies in multiple sclerosis pathogenesis and therapy. Nat Rev Neurol 8:613-623

8. Lucchinetti C, Brueck W, Parisi J, Scheithauer B, Rodriguez M, Lassmann H (2000) Heterogeneity of multiple sclerosis lesions: implications for the pathogenesis of demyelination. Ann Neurol 47:707-717

9. Cortese I, Chaudhry V, So YT, Cantor F, Cornblath DR, Rae-Grant A (2011) Evidence-based guideline update: Plasmapheresis in neurologic disorders: report of the Therapeutics and Technology Assessment Subcommittee of the American Academy of Neurology. Neurology 3:294-300

10. Srivastava R, Aslam M, Kalluri SR, Schirmer L, Buck D, Tackenberg B, Rothhammer V, Chan A, Gold R, Berthele A, Bennett JL, Korn T, Hemmer B (2012) Potassium channel KIR4.1 as an immune target in multiple sclerosis. N Engl J Med 367:115-123

11. Pierson ER, Stromnes IM, Goverman JM (2014) B cells promote induction of experimental autoimmune encephalomyelitis by facilitating reactivation of $T$ cells in the central nervous system. J Immunol 3:929-939

12. Hauser SL, Waubant E, Arnold DL (2008) B-cell depletion with rituximab in relapsing-remitting multiple sclerosis. N Engl J Med 358:676-688

13. Freedman MS, Kaplan JM, Markovic-Plese S (2013) Insights into the mechanisms of the therapeutic efficacy of alemtuzumab in multiple sclerosis. J Clin Cell Immunol 4:1000152

14. Sorensen PS, Lisby S, Grove R, Derosier F, Shackelford S, Havrdova E, Drulovic J, Filippi M (2014) Safety and efficacy of ofatumumab in relapsingremitting multiple sclerosis: a phase 2 study. Neurology 82:573-581

15. Kuerten S, Pommerschein G, Barth SK, Hohmann C, Milles B, Sammer FW, Duffy CE, Wunsch M, Rovituso DM, Schroeter M, Addicks K, Kaiser CC, Lehmann PV (2014) Identification of a B cell-dependent subpopulation of multiple sclerosis by measurements of brain-reactive $B$ cells in the blood. Clin Immunol 152:20-24

16. Polman CH, Reingold SC, Banwell B, Clanet M, Cohen JA, Filippi M, Fujihara K, Havrdova E, Hutchinson M, Kappos L, Lublin FD, Montalban X, O'Connor P, Sandberg-Wollheim M, Thompson AJ, Waubant E, Weinshenker B, Wolinsky JS (2011) Diagnostic criteria for multiple sclerosis: 2010 revisions to the McDonald criteria. Ann Neurol 69:292-302

17. Kurtzke JF (1983) Rating neurologic impairment in multiple sclerosis: an Expanded Disability Status Scale (EDSS). Neurology 33:1444-1452

18. MSBase Foundation Ltd. The MS Severity Rank Calculator MS Curves. Accessed March 29, 2014, 2:25 p.m., at http://www.msbase.org

19. Pinna D, Corti D, Jarrossay D, Sallusto F, Lanzavecchia A (2009) Clonal dissection of the human memory B-cell repertoire following infection and vaccination. Eur J Immunol 39:1260-1270

20. Lill-Elghanian D, Schwartz K, King L, Fraker P (2002) Glucocorticoid-induced apoptosis in early $B$ cells from human bone marrow. Exp Biol Med (Maywood) 227:763-770

21. Meinl E, Krumbholz M, Hohlfeld R (2006) B lineage cells in the inflammatory central nervous system environment: migration, maintenance, local antibody production, and therapeutic modulation. Ann Neurol 59:880-892

22. Qin Y, Duquette P, Zhang Y, Talbot P, Poole R, Antel J (1998) Clonal expansion and somatic hypermutation of $\mathrm{V}(\mathrm{H})$ genes of $\mathrm{B}$ cells from cerebrospinal fluid in multiple sclerosis. J Clin Invest 102:1045-1050 
23. Genain CP, Cannella B, Hauser SL, Raine CS (1999) Identification of autoantibodies associated with myelin damage in multiple sclerosis. Nat Med 5:170-175

24. Reindl M, Khalil M, Berger T (2006) Antibodies as biological markers for pathophysiological processes in MS. J Neuroimmunol 180:50-62

25. Karni A, Bakimer-Kleiner R, Abramsky O, Ben-Nun A (1999) Elevated levels of antibody to myelin oligodendrocyte glycoprotein is not specific for patients with multiple sclerosis. Arch Neurol 56:311-315

26. Keegan M, Konig F, McClelland R, Brück W, Morales Y, Bitsch A, Panitch H, Lassmann H, Weinshenker B, Rodriguez M, Parisi J, Lucchinetti CF (2005) Relation between humoral pathological changes in multiple sclerosis and response to therapeutic plasma exchange. Lancet 366:579-582

27. Berger T, Rubner P, Schautzer F, Egg R, Ulmer H, Mayringer I, Dilitz E, Deisenhammer F, Reindl M (2003) Antimyelin antibodies as a predictor of clinically definite multiple sclerosis after a first demyelinating event. N Engl J Med 349:139-145

28. Kuhle J, Pohl C, Mehling M, Edan G, Freedman MS, Hartung HP, Polman CH, Miller DH, Montalban X, Barkhof F, Bauer L, Dahms S, Lindberg R, Kappos L, Sandbrink R (2007) Lack of association between antimyelin antibodies and progression to multiple sclerosis. N Engl J Med 356:371-378

29. Sun J, Link H, Olsson T, Xiao BG, Andersson G, Ekre HP, Linington C, Diener P (1991) T and B cell responses to myelin-oligodendrocyte glycoprotein in multiple sclerosis. J Immunol 146:1490-1495

30. Sun JB, Olsson T, Wang WZ, Xiao BG, Kostulas V, Fredrikson S, Ekre HP, Link H (1991) Autoreactive T and B cells responding to myelin proteolipid protein in multiple sclerosis and controls. Eur J Immunol 21:1461-1468

doi:10.1186/s40478-014-0138-2

Cite this article as: Hohmann et al:: Categorization of multiple sclerosis relapse subtypes by B cell profiling in the blood. Acta Neuropathologica Communications 2014 2:138.

\section{Submit your next manuscript to BioMed Central and take full advantage of:}

- Convenient online submission

- Thorough peer review

- No space constraints or color figure charges

- Immediate publication on acceptance

- Inclusion in PubMed, CAS, Scopus and Google Scholar

- Research which is freely available for redistribution 